Applied nutritional investigation

\title{
Bioimpedance vector analysis and conventional bioimpedance to assess body composition in older adults with dementia
}

\author{
María Alicia Camina Martín M.S. ${ }^{\mathrm{a}, *}$, Beatriz de Mateo Silleras Ph.D. ${ }^{\mathrm{a}}$, \\ Lexa Nescolarde Selva Ph.D. ${ }^{\mathrm{b}}$, Sara Barrera Ortega M.S. ${ }^{\mathrm{c}}$, \\ Luis Domínguez Rodríguez M.S. ${ }^{c}$, María Paz Redondo del Río Ph.D., M.D. ${ }^{\text {a }}$
}

${ }^{a}$ Area of Nutrition and Food Science, Faculty of Medicine, Universidad de Valladolid, Valladolid, Spain

${ }^{\mathrm{b}}$ Department of Electronic Engineering, Universitat Politècnica de Catalunya, Barcelona, Spain

${ }^{\mathrm{c}}$ Residential Care Centre San Juan de Dios, Psychogeriatric Area, Palencia, Spain

\section{A R T I C L E I N F O}

\section{Article history:}

Received 5 February 2014

Accepted 19 June 2014

\section{Keywords:}

Body composition

Bioelectrical impedance vector analysis

Conventional bioimpedance analysis

Elderly

Dementia

\begin{abstract}
A B S T R A C T
Objective: Although dementia and nutritional status have been shown to be strongly associated, differences in body composition (BC) among older people with dementia have not yet been firmly established. The aim of this study was to assess BC through conventional and vector bioimpedance analysis (BIA and BIVA, respectively) in a sample of institutionalized older men with and without dementia, in order to detect dementia-related BC changes.

Methods: Forty-one institutionalized men ages $\geq 65$ y (23 without dementia [CG] and 18 with dementia [DG]) were measured with BIA and interpreted with BIVA and predictive equations. Results: Age (74.4 and $75.7 \mathrm{y}$ ) and body mass index (22.5 and $23.6 \mathrm{~kg} / \mathrm{m}^{2}$ ) were similar for DG and $\mathrm{CG}$, respectively. Resistance and ratio of resistance to height did not differ significantly between the two groups. Reactance and ratio of reactance to height were $21.2 \%$ and $20.4 \%$ lower in DG than in CG. Phase angle was significantly lower in DG (mean $=4.0 ; 95 \%$ confidence interval $[\mathrm{CI}], 3.6^{\circ}-4.3^{\circ}$ ) than in $\mathrm{CG}\left(\right.$ mean $\left.=4.7 ; 95 \% \mathrm{CI}, 4.3^{\circ}-5.1^{\circ}\right)$. Mean fat mass index $\left(6\right.$ and $\left.7 \mathrm{~kg} / \mathrm{m}^{2}\right)$, and mean fat-free mass index $\left(16.4\right.$ and $\left.16.6 \mathrm{~kg} / \mathrm{m}^{2}\right)$ were similar in both groups. BIVA showed a significant downward migration of the ellipse in DG with respect to CG $\left(T^{2}=15.1 ; P<0.01\right)$.

Conclusion: Conventional BIA showed no significant differences in BC between DG and CG, although reactance and ratio of reactance to height were about $21 \%$ lower in DG. Nevertheless, a body cell mass depletion and an increase in the ratio of extracellular to intracellular water were identified in DG using BIVA. BIVA reflects dementia-related changes in BC better than BIA.
\end{abstract}

(c) 2015 Elsevier Inc. All rights reserved.

\section{Introduction}

Dementia and body composition (BC) have been shown to be strongly associated, but there are still conflicting data on the nature of this association. On the one hand, it has been recently evidenced that high body mass index (BMI) values, and hence

\footnotetext{
MACM was involved in the conception and design of the study; generation, collection, assembly, analysis, and interpretation of data; and drafting of the manuscript. BdMS and MPRdR were involved in the conception and design of the study; analysis and interpretation of data; and revision of the manuscript. LNS was responsible for revision of the manuscript and critical input. SBO and LDR assisted in the generation, collection, and assembly of data. All authors approved the final version of the manuscript. The authors reported no financial conflicts of interest.

* Corresponding author. Tel.: +34 983185249; fax: +34 983183812.

E-mail address: Aliciacamina@gmail.com (M. A. Camina Martín).
}

adiposity, in adulthood are associated with an increased risk for Alzheimer's disease (AD) and vascular dementia (VD) in late life $[1,2]$; on the other hand, it is well known that malnutrition and particularly unintentional weight loss are common clinical features in patients with dementia, which occur at the preclinical stage of the disease and are maintained at the follow-up, further aggravating the prognosis of these patients [3].

The relationship between BMI and dementia at older ages is less clear [4]. The Cardiovascular Health Study recently reported that the risk for dementia was positively associated with obesity at age $50 \mathrm{y}$, but negatively associated with BMI after age 65 [5]. Several epidemiologic studies also suggested that overweight and obesity in late life are associated with reduced risk for dementia [6,7], whereas others have found that a higher BMI at older ages predicts dementia [8]. Because it is widely accepted that malnutrition and unintended weight loss not only occur 
during the final stages of the disease, but also may be a precursor to dementia $[9,10]$, the term obesity paradox has been proposed to describe the relationship between BMI in older adults and risk for dementia.

Despite the evidence showing a role of adiposity during adulthood in the subsequent development of dementia, data available on changes in BC in older individuals with dementia have not yet been firmly established. Several factors contribute to this situation. Probably the most notable factor is the method used to measure adiposity. Both BMI and waist circumference (WC) have been employed as indicators of adiposity (overall and central adiposity, respectively) in most studies, but currently there is no consensus on the cutoff points for obesity for the elderly [11,12]. Additionally, age-related changes in BC and loss of height alter the association between BMI and percentage body fat [13].

On the other hand, it has been demonstrated that a few isolated anthropometric measurements, such as calf circumference, are good indicators of BC in this population [14]. Nevertheless, the applicability of the anthropometry to estimate $\mathrm{BC}$ in this population also presents a number of challenges and constraints. We recently evidenced that the predictive equations based on anthropometric measurements leads to significant underestimation of fat mass (FM) in older individuals with dementia [14].

Bioelectrical impedance analysis (BIA) is valid for BC analysis in this population when using the specific equations developed and validated in this group [15]. Nevertheless, age-related changes in the amount (hypo- or hyperhydration) and distribution (intra- or extracellular) of body water are relatively common in older institutionalized individuals [16] and may lead to significant errors in estimating body compartments [17] because of assumptions of a constant hydration of the fat-free mass (FFM) [18].

In the vectorial approach of BIA, called bioelectrical impedance vector analysis (BIVA), the individual components of the impedance vector, resistance $(\mathrm{R})$ and reactance $(\mathrm{Xc})$, are normalized by the height of the subject $(\mathrm{R} / \mathrm{H}$ and $\mathrm{Xc} / \mathrm{H})$ and represented in the $\mathrm{R}-\mathrm{Xc}$ graph (abscissa, $\mathrm{R} / \mathrm{H}$; ordinate, $\mathrm{Xc} / \mathrm{H}$ ) [19]. $R$ is inversely related to the intra- and extracellular water (ICW and ECW), whereas Xc is directly related to the amount of soft tissue structures (mass). Therefore, vector length is influenced by tissue hydration (shortening indicates overhydration, and lengthening suggests dehydration), and vector direction (i.e., phase angle [PA]) is influenced by the amount of cell mass contained in soft tissues (a small PA indicates malnutritioncachexia-anorexia; a large PA may be observed in both obese and athletic individuals). The vector derived for an individual is compared against the normal interval of the healthy, reference population, and is expressed in percentiles of the normal distribution of a bivariate, probabilistic graph. Therefore, BIVA does not yield any absolute estimates of body compartment [20], but it allows assessing changes in both $\mathrm{BC}$ and the hydration status. BIVA is simpler and more affordable than dual-energy $\mathrm{x}$-ray absorptiometry (DXA; a commonly used reference method) and, in contrast to anthropometric measurements or conventional BIA, is unaffected by regression adjustments that may introduce clinically relevant bias [20].

Recent studies also emphasize in the role of PA, calculated as arc tan reactance/resistance and expressed in degrees, as a practical indicator of functional and nutritional status in the older population [21]. It also provides information about the clinical outcome and mortality, which is another important advantage of BIVA [22,23].

The objective of this study was to assess BC through BIA and BIVA in a sample of institutionalized older men, including a group of nondemented men and a group of demented men, to detect dementia-related BC changes.

We sought to overcome the limitations of BMI as a general indicator of adiposity by using BIA to estimate BC and BIVA to categorize soft tissue mass and hydration.

\section{Materials and methods}

Participants and design

This was a cross-sectional study carried out on a sample of older men institutionalized in the Psychogeriatric Area of the Residential Care Centre San Juan de Dios (Palencia, Spain). Inclusion criteria were being white, male, aged $\geq 65 \mathrm{y}$, and at risk for malnutrition or having normal weight on the basis of the BMI cutoffs established for this age group (18.5-21.9 kg/m² and 22-26.9 kg/m², respectively) [24]. Individuals were excluded if they showed clinical signs of hydration imbalance, had ongoing acute illness, or had pacemakers or metal implants.

The sample consisted of 41 participants ages 65 to $96 \mathrm{y} ; 18$ (43.9\%) with dementia according to criteria from the Diagnostic and Statistical Manual of Mental Disorders, Fourth Edition [25] (dementia group, DG), and 23 (56.1\%) without dementia (control group, CG). All men with dementia were in moderately severe to very severe stages, corresponding to stages 5 to 7 on the Global Deterioration Scale (GDS) [26], and the subtypes of dementia were AD, VD and mixed dementia (MD). The control group consisted of institutionalized men without dementia, matched for age, BMI, and comorbidities.

One trained individual performed anthropometric and recumbent hand-tofood bioelectrical impedance measurements first thing in the morning, following an overnight fast. This study was conducted in accordance with the Declaration of Helsinki and all procedures involving human participants were approved by the Ethics Committee of the Residential Care Centre San Juan de Dios on April 2010. Written informed consent was obtained from the legal guardians of all participants included in the study.

\section{Anthropometry}

Anthropometric measurements were performed according to the protocol of the Spanish Society for Parenteral and Enteral Nutrition and the Spanish Society of Geriatric Medicine and Gerontology [24]. Body weight (W; kg) was measured to the nearest $100 \mathrm{~g}$, using a SECA 954 chair scale with the participant wearing underwear; and height $(\mathrm{H} ; \mathrm{m})$ was estimated from a knee height measurement using a previously described equation [27]. WC and calf circumference (CC) were measured with a flexible, inelastic measuring tape (to the nearest $1 \mathrm{~cm}$ ).

\section{Body composition analysis}

\section{Bioimpedance measurements}

Whole-body impedance measurements were made using a standard protocol [28]. A $50 \mathrm{kHz}$, tetra-polar, phase-sensitive BIA (BIA-101; AKERN-Srl, Florence, Italy) introduced a sinusoidal, alternating current of $400 \mu \mathrm{A}$ RMS to measure $\mathrm{R}$, $\mathrm{Xc}$, and PA. Measurement errors of the system, determined with a precision resistor and capacitor, were $<1 \%$ for $\mathrm{R}$ and $<2 \%$ for capacitance.

$B I A$

The amount of FFM $(\mathrm{kg})$ was estimated with the prediction equation for BIA in adults ages 20 to 94 y [29]. Previous studies evidenced that this equation was accurate in our sample of older individuals [14]. FFM and FM indices (FFMI and FMI, respectively) were calculated as FMI $\left(\mathrm{kg} / \mathrm{m}^{2}\right)=\mathrm{FM} / \mathrm{H}^{2}$, and FFMI $\left(\mathrm{kg} / \mathrm{m}^{2}\right)=$ $\mathrm{FFM} / \mathrm{H}^{2}$. These indices were used to compare the $\mathrm{BC}$ data obtained in this study with the reference $\mathrm{BC}$ data for whites [30].

\section{BIVA}

In this study, the reference bivariate tolerance ellipses (50\%, 75\%, and $95 \%$ of the distribution of the values in general population) for the adult and older men [31] were used for the qualitative and semiquantitative assessment of BC and hydration status in each individual. The $95 \%$ confidence ellipses for mean vectors of the DG and the CG were drawn to compare these groups.

\section{Statistical analysis}

Statistical analysis was carried out using the SPSS ${ }^{\circledR}$ version 18.0 (SPSS, Chicago, IL, USA). All data are presented as mean (95\% confidence interval). The normality of the distribution of the variables was checked by the Shapiro-Wilk test and the homogeneity of variances by Levene's test. $t$ Tests were used for pairwise comparisons. The level of significance was set at $P<0.05$. 
In BIVA analysis, statistically significant differences between the mean vectors were determined with the Hotelling's $T^{2}$ test for vector analysis, which is a multivariate extension of the Student's test for unpaired data in comparison of mean vectors from two groups. Two mean vectors have a significantly different $(P<0.05)$ position in the RXc graph if their $95 \%$ confidence ellipses are separated according to Hotelling's $T^{2}$ test [32]. Overlapping ellipses are not significantly different $(P>0.05)$.

\section{Results}

The demented group consisted of 18 men ages $74.4 \mathrm{y}$ (range 65-92 y), whose mean BMI was $22.5 \mathrm{~kg} / \mathrm{m}^{2}$ (95\% CI, 20.7-24.2 $\left.\mathrm{kg} / \mathrm{m}^{2}\right)$. In the control group $(\mathrm{n}=23)$, the mean age was $75.7 \mathrm{y}$ (range 66-96 y) and the mean BMI was $23.6 \mathrm{~kg} / \mathrm{m}^{2}$ (95\% CI, 22.7$24.4 \mathrm{~kg} / \mathrm{m}^{2}$ ). Age and BMI between the groups were not significantly different. Anthropometric measurements also were similar between the groups, except in the CC, which was significantly higher in the control group (Table 1 ).

Table 2 shows the differences in the BIA measurements and estimated $\mathrm{BC}$ variables between the groups. The DG had significantly lower values of $\mathrm{Xc}, \mathrm{Xc} / \mathrm{H}$, and $\mathrm{PA}$ with no significant differences in $\mathrm{R}$ and $\mathrm{R} / \mathrm{H}$ compared with $\mathrm{CG}$. The impedancepredicted relative measures of FM and FFM (FM\%, FFM\%, FMI and FFMI) and FFMI were similar between the groups.

The mean impedance vectors and 95\% confidence ellipses were significantly different $\left(T^{2}=15.1 ; P<0.01\right)$ between the two groups (Fig. 1). The ellipse of the DG was shifted downward.

The position of the individual vectors of all of men was to the right of the major axis of the reference population (Fig. 2). The individual vectors of men in the DG group were in the lowerright quadrant and most of those for the CG (60.8\%) in the upper-right quadrant. Furthermore, $66.7 \%$ of the vectors of the men included in the DG and 56.5\% of those included in CG fell outside the $75 \%$ tolerance ellipse.

\section{Discussion}

Several epidemiologic studies have reported an association between high levels of adiposity in adulthood and an increased risk for developing both $A D$ and VD in old age [1,2]. Thus, we hypothesized that individuals with dementia would have a higher FM than those in the control group. However, the findings of the present study did not support this hypothesis. The BIA predictions of FM or FFM found no differences between the groups. However, use of BIVA identified a significant depletion in body cell mass (BCM) in the DG compared with the CG group.

Body compartment volumes were not estimated from the anthropometric parameters because this method has been found to have a low level of accuracy in populations ages $>60 \mathrm{y}[33,34]$. Nevertheless, some specific anthropometric measurements, such as WC and CC, deserve special attention in this population because of their correlation with fat and muscle mass, respectively. In this regard, no significant differences were found

Table 1

Descriptive statistics of the anthropometric measurements

\begin{tabular}{lll}
\hline & $\begin{array}{l}\text { Demented men } \\
(\mathrm{n}=18)\end{array}$ & $\begin{array}{l}\text { Nondemented men } \\
(\mathrm{n}=23)\end{array}$ \\
\hline Weight $(\mathrm{kg})$ & $60.7(54.6-66.7)$ & $64.1(60.8-67.4)$ \\
Height $(\mathrm{m})$ & $1.64(1.57-1.71)$ & $1.65(1.62-1.68)$ \\
BMI $\left(\mathrm{kg} / \mathrm{m}^{2}\right)$ & $22.5(20.7-24.2)$ & $23.6(22.7-24.4)$ \\
Waist circumference $(\mathrm{cm})$ & $90.1(85.6-94.5)$ & $93.2(89.9-96.5)$ \\
Calf circumference $(\mathrm{cm})$ & $34.0(30.7-37.3)^{*}$ & $36.0(34.6-37.2)$ \\
\hline
\end{tabular}

Results are expressed as mean $(95 \% \mathrm{CI})$

$* P<0.05$.
Table 2

Bioelectrical and body composition variables

\begin{tabular}{lcc}
\hline & Demented men $(\mathrm{n}=18)$ & Nondemented men $(\mathrm{n}=23)$ \\
\hline $\mathrm{R}(\Omega)$ & $568.1(530.2-605.9)$ & $601.0(571.6-630.5)$ \\
$\mathrm{Xc}(\Omega)$ & $38.9(35.4-42.5)^{*}$ & $49.4(45.8-53.1)$ \\
$\mathrm{PA}($ degrees $)$ & $4.0(3.6-4.3)^{\dagger}$ & $4.7(4.3-5.1)$ \\
$\mathrm{R} / \mathrm{H}(\Omega / \mathrm{m})$ & $349.6(323.5-375.6)$ & $365.8(345.9-385.8)$ \\
$\mathrm{Xc} / \mathrm{H}(\Omega / \mathrm{m})$ & $23.9(21.7-26.2)^{*}$ & $30.1(27.7-32.5)$ \\
$\mathrm{FM}(\mathrm{kg})$ & $15.8(13.6-18.0)^{\ddagger}$ & $19.0(17.0-21.1)$ \\
$\mathrm{FM}(\%)$ & $26.4(23.6-29.2)$ & $29.4(27.1-31.6)$ \\
$\mathrm{FMI}\left(\mathrm{kg} / \mathrm{m}^{2}\right)$ & $6.0(5.2-6.8)$ & $7.0(6.3-7.7)$ \\
FFM $(\mathrm{kg})$ & $43.7(40.9-46.6)$ & $45.1(43.0-47.2)$ \\
$\mathrm{FFM}(\%)$ & $73.6(70.8-76.4)$ & $70.7(68.4-72.9)$ \\
FFMI $\left(\mathrm{kg} / \mathrm{m}^{2}\right)$ & $16.4(15.7-17.1)$ & $16.6(16.1-17.1)$ \\
\hline
\end{tabular}

FFM, fat-free mass; FFMI, fat-free mass index; FM, fat mass; FMI, fat mass index; $\mathrm{R}$, resistance; $\mathrm{R} / \mathrm{H}$, reactance standardized by height; $\mathrm{Xc}$, reactance; $\mathrm{Xc} / \mathrm{H}$, resistance standardized by height

Results are expressed as mean $(95 \% \mathrm{CI})$

$* P<0.001$.

$P<0.01$.

$\ddagger P<0.05$.

between the groups in WC, but the CC was significantly lower in the DG (Table 1), which may suggest a higher level of muscle-related disability in these individuals [35].

With regard to the conventional BIA, contrary to expectations, we found no significant differences in the mean values of the relative FM and FFM measures (i.e., percentages and indexes) estimated through predictive equations (Table 2). According to the reference percentiles in whites [30], the mean values of the FMI were around the 50 th percentile $\left(6.4 \mathrm{~kg} / \mathrm{m}^{2}\right)$ in both groups, whereas the mean values of the FFMI were around the fifth percentile $\left(16.6 \mathrm{~kg} / \mathrm{m}^{2}\right)$ (Table 2). This could be consequence of the shortcomings of using conventional BIA in older individuals, mainly because of assumptions of a constant composition of the fat-free body (e.g., hydration of the FFM and constant ratio of protein to bone).

When using the confidence ellipses (BIVA) to compare the groups, the mean value of the PA was found to be lower in the DG (Fig. 1). It must be emphasized that this was due to a smaller Xc/ $\mathrm{H}$ component with a comparable $\mathrm{R} / \mathrm{H}$ (Table 2). In this context, it should be pointed out that Xc and Xc/H for the DG were $20.4 \%$ and a $21 \%$ lower than for the CG, respectively. In contrast, insignificant percentages changes in $\mathrm{R}$ and $\mathrm{R} / \mathrm{H}(5.5 \%$ and $4.4 \%$, respectively) were found between both groups. Given that $\mathrm{Xc}$ is directly related to the amount of soft tissue structures, and that $\mathrm{R}$ is inversely related to the ICW and ECW, this finding clearly indicates an alteration in BCM with a comparable amount of total body water in the groups, as can be observed in Figure 1. Our findings are in agreement with previous studies performed with BIVA, in which patterns in patients with AD were also characterized by a reduction in $\mathrm{Xc} / \mathrm{H}$ values with preserved $\mathrm{R} / \mathrm{H}[36,37]$.

The results obtained through BIVA and BIA analyses of BC are not incompatible; actually we are referring to two different levels of BC analysis: the cellular and molecular models. Through the BIA approach, we employed a predictive equation of FFM $(\mathrm{kg})$, and the FM $(\mathrm{kg})$ was calculated as body mass $(\mathrm{kg})$ minus FFM (kg). Hence, we analyzed the BC on the basis of the twocompartment model, and therefore at the molecular level [38]. In contrast, the R-Xc graphs (i.e., BIVA) allow a semiquantitative assessment of the hydration status and the individual's BCM. Considering $\mathrm{BCM}$, we were actually analyzing the $\mathrm{BC}$ at the cellular level on the basis of the four-compartment model, in which the BM is the sum of the FM, BCM, extracellular fluids and extracellular solids [38]. The BCM comprises the cellular components of muscles and viscera, including the ICW but not the 


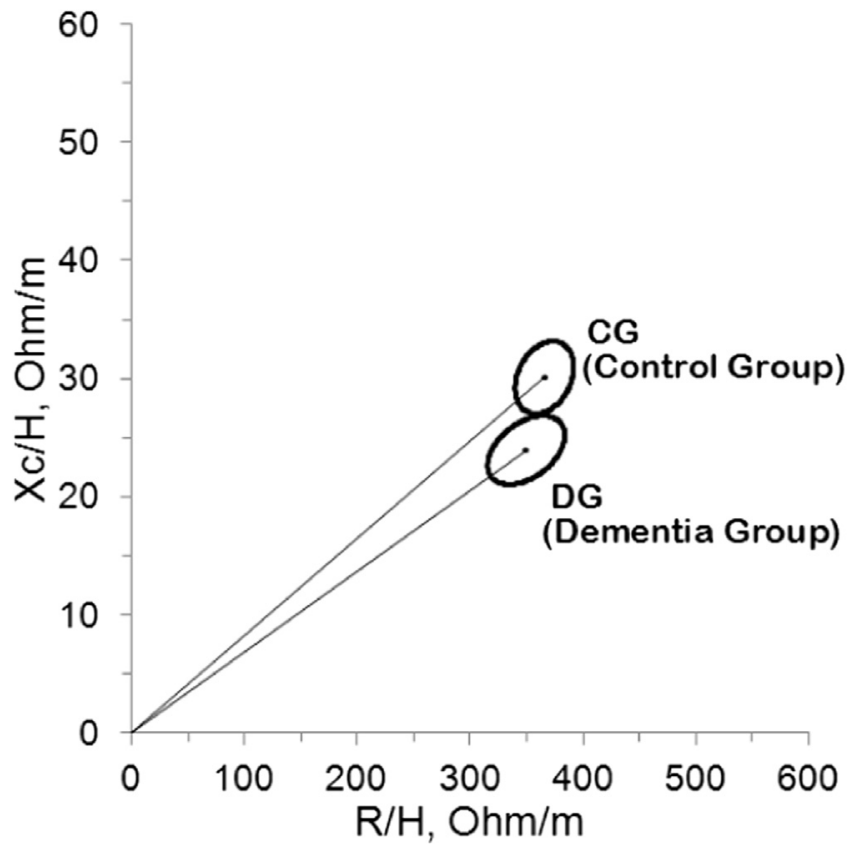

$\mathrm{T}^{2}=15.1(\mathrm{p}<0.01)$

Fig. 1. Mean impedance vectors and confidence ellipses for men with dementia $(\mathrm{n}=18)$ and without dementia $(\mathrm{n}=23)$. CG, control group; $\mathrm{DG}$, dementia group; $\mathrm{R} / \mathrm{H}$, reactance standardized by height; $\mathrm{Xc} / \mathrm{H}$, resistance standardized by height.

stored fat lipids within them. Therefore, the BCM can also be defined as the FFM minus the extracellular mass (i.e., the bone mineral, and ECW), and consequently, a depleted level of BCM in the DG with respect to the CG is plausible even without significant differences in FFM between the groups.

These findings suggest, in turn, a change in the FFM composition in the DG with respect to the CG, characterized by a relative increase in ECW with respect to ICW that can be interpreted as a low number of cells per unit volume [36]. This in turn could be compatible with a greater loss of skeletal muscle mass (SMM) because the decrease in SMM has been shown to be greater than that of the non-muscle lean (organ) mass in older adults [39,40]. Figure 1 clearly indicates a BCM (and not FFM) depletion and a higher ratio of ECW to ICW in the DG, considering that 1) a high $\mathrm{R}$ is correlated to small amounts of FFM; 2) for the same body mass, a low Xc indicates a decrease in the amount of BCM; and 3) a decrease in PA may be due both to a worsening in the hydration of the FFM and a decrease in the amount of the BCM relative to the amount of the FFM. An increase in the ratio of ECW to ICW is expected as a result of the decrease in BCM, which, in turn, may be attributed to protein-energy malnutrition [41], fast weight loss [42], or catabolic stress [43], as well as to elevated adiposity levels [44-46]. It has been suggested that under these circumstances the assessment of BCM is especially important, because its depletion (as well as that of the SMM) may be masked by normal values of FFM [47], as was observed in our sample comparing DG with CG.

On the other hand, it is necessary to note that more than $50 \%$ of the individual impedance vectors $(66.7 \%$ of the vectors of the DG and $56.5 \%$ of the vectors of the CG) fell outside the 75\% tolerance ellipse (Fig. 2), indicating abnormal tissue impedance in these patients [31]. This condition may contribute

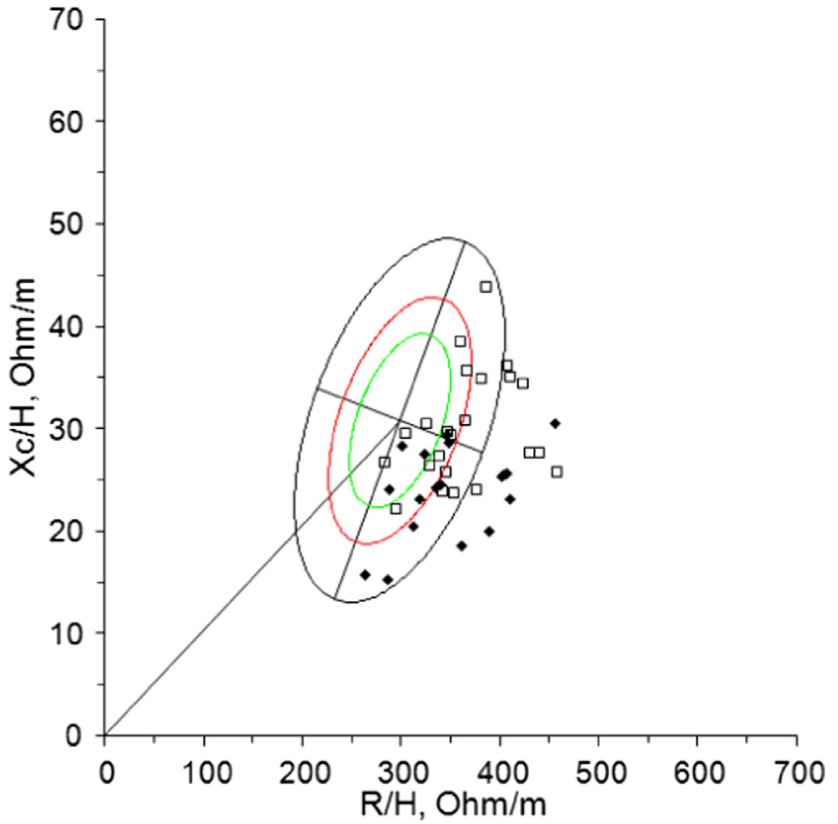

Dementia Group (DG), dark points; Control Group (CG), white points.

Fig. 2. Individual impedance vectors from men with dementia $(n=18)$ and without dementia $(n=23)$. CG, control group; $D G$, dementia group; $R / H$, reactance standardized by height; $\mathrm{Xc} / \mathrm{H}$, resistance standardized by height.

to large prediction errors in estimating the volumes of body compartments through the conventional BIA approach. In fact, it has been demonstrated that the agreement between BIA and DXA was not as strong when applied in undernourished older individuals [48]. Furthermore, this might explain the discrepancies found in previous studies using BIA to analyze dementiarelated changes in BC $[49,50]$.

Finally, as previously stated, BIVA allows a semiquantitative assessment of BC, and hence we could not check the accuracy of the predictive equations based on BIA in this sample. Nevertheless, the assumed bias was the same in both groups and, independently of the accuracy of the predictions of FM and FFM, the BIVA patterns were consistent with the results showed by the conventional BIA approach.

The main limitation of this study is the sample size. However, the selection criteria established were strict to control all potential confounding variables. Specifically, the main determinants of $\mathrm{BC}$ (ethnicity, sex, age, and degree of mobility) were controlled in the study design (data not shown). BMI also was considered in the study design because it is necessary for the correct interpretation of both the vector distribution patterns and the FMI and FFMI. All this ensures the comparability between the two study groups.

\section{Conclusion}

Conventional BIA showed no significant differences in BC between the two groups, although $\mathrm{Xc}$ and $\mathrm{Xc} / \mathrm{H}$ were about $21 \%$ lower in DG with respect to CG. BCM depletion and an increase in the ratio of ECW to ICW were evidenced in the dementia group using BIVA. BIVA reflects dementia-related changes in BC better than BIA. 


\section{References}

[1] Whitmer RA, Gunderson EP, Quesemberry CP Jr, Zhou J, Yaffe K. Body mass index in midlife and risk of Alzheimer disease and vascular dementia. Curr Alzheimer Res 2007;4:103-9.

[2] Kivipelto M, Ngandu T, Fratiglioni L, Viitanen M, Kåreholt I, Winblad B, et al. Obesity and vascular risk factors at midlife and the risk of dementia and Alzheimer disease. Arch Neurol 2005;62:1556-60.

[3] Guerin O, Andrieu S, Schneider SM, Cortes F, Cantet C, Gillette-Guyonnet S, et al. Characteristics of Alzheimer's disease patients with a rapid weight loss during a six-year follow-up. Clin Nutr 2009;28:141-6.

[4] West NA, Haan MN. Body adiposity in late life and risk of dementia or cognitive impairment in a longitudinal community-based study. J Gerontol A Biol Sci Med Sci 2009;64:103-9.

[5] Fitzpatrick AL, Kuller LH, Lopez OL, Diehr P, O'Meara ES, Longstreth WT Jr, et al. Midlife and late-life obesity and the risk of dementia: Cardiovascular Health Study. Arch Neurol 2009;66:336-42.

[6] Doruk H, Naharci MI, Bozoglu E, Isik AT, Kilic S. The relationship between body mass index and incidental mild cognitive impairment, Alzheimer's disease and vascular dementia in elderly. J Nutr Health Aging 2010;14:834-8.

[7] Hughes TF, Borenstein AR, Schofield E, Wu Y, Larson EB. Association between late-life body mass index and dementia: the Kame Project. Neurology 2009;72:1741-6.

[8] Chang WS, Won KH, Lee JY, Kim ET, Kweon HJ. The relationship between obesity and the high probability of dementia based on the body mass index and waist circumference. Korean J Fam Med 2012;33:17-24.

[9] Tolppanen AM, Ngandu T, Kăreholt I, Laatikainen T, Rusanen $M$, Soininen $\mathrm{H}$, et al. Midlife and late-life body mass index and late-life dementia: results from a prospective population-based cohort. J Alzheimers Dis 2014;38:201-9.

[10] Grundman M. Weight loss in the elderly may be a sign of impending dementia. Arch Neurol 2005;62:20-2.

[11] Wang Y, Rimm EB, Stampfer MJ, Willett WC, Hu FB. Comparison of abdominal adiposity and overall obesity in predicting risk of type 2 diabetes among men. Am J Clin Nutr 2005;81:555-63.

[12] Wildman RP, Gu D, Reynolds K, Duan X, He J. Appropriate body mass index and waist circumference cut-offs for categorization of overweight and central adiposity among Chinese adults. Am J Clin Nutr 2004;80: 1129-36.

[13] Villareal DT, Apovian CM, Kushner RF, Klein S, American Society for Nutrition, NAASO, The Obesity Society. Obesity in older adults: technical review and position statement of the American Society for Nutrition and NAASO, The Obesity Society. Obes Res 2005;13:1849-63.

[14] Camina Martín MA, de Mateo Silleras B, Carreño Enciso L, de la Cruz Marcos S, Miján de la Torre A, Redondo del Río P. Changes in body composition in relation to the stage of dementia in a group of institutionalized elderly. Nutr Hosp 2013;28:1093-101.

[15] Lohman TG. Advances in body composition assessment. Champaign, IL: Human Kinetics; 1992:1-24. 37-56.

[16] Deurenberg P. The dependency of bioelectrical impedance on intra and extracellular water distribution. In: Kral JG, Van Itallie TB, editors. Recent development in body composition analysis: methods and applications. London: Smith-Gordon; 1993. p. 43-8.

[17] Rösler A, Lehmann F, Krause T, Wirth R, von Renteln-Kruse W. Nutritional and hydration status in elderly subjects: clinical rating versus bioimpedance analysis. Arch Gerontol Geriatr 2010;50:e81-5.

[18] Withers RT, Laforgia J, Heymsfield SB. Critical appraisal of the estimation of body composition via two-, three-, and four-compartment models. Am J Hum Biol 1999;11:175-85.

[19] Piccoli A, Rossi B, Pillon L, Bucciante G. A new method for monitoring body fluid variation by bioimpedance analysis: the RXc graph. Kidney Int 1994;46:534-9.

[20] Nescolarde L, Núñez A, Bogónez-Franco P, Lara A, Vaillant G, Morales R, et al. Reference values of the bioimpedance vector components in a Caribbean population. ESPEN J 2013;8:e141-4.

[21] Norman K, Stobäus N, Pirlich M, Bosy-Westphal A. Bioelectrical phase angle and impedance vector analysis-clinical relevance and applicability of impedance parameters. Clin Nutr 2012;31:854-61.

[22] Wilhelm-Leen ER, Hall YN, Horwitz RI, Chertow GM. Phase angle, frailty and mortality in older adults. J Gen Intern Med 2014;29:147-54.

[23] Wirth R, Volkert D, Rösler A, Sieber CC, Bauer JM. Bioelectric impedance phase angle is associated with hospital mortality of geriatric patients. Arch Gerontol Geriatr 2010;51:290-4.

[24] Wanden-Berghe C. Valoración Antropométrica. In: Planas M, editor. Valoración Nutricional en el Anciano. Madrid: GalénitasNigra-Trea; 2006. p. 77-96.

[25] American Psychiatric Association. Diagnostic and statistical manual of mental disorders, fourth edition (DSM IV). Washington, DC: APA; 1997.
[26] Reisberg B, Ferris SH, De León MJ, Crook T. The Global Deterioration Scale for assessment of primary degenerative dementia. Am J Psychiatry 1982;139:1136-9.

[27] Chumlea WC, Roche AF, Steinbaugh ML. Estimating stature from knee height for persons 60 to 90 y of age. J Am Geriatr Soc 1985;33:116-20.

[28] Lukaski HC. Assessment of body composition using tetrapolar impedance analysis. In: Whitehead RG, Prentice A, editors. New techniques in nutritional research. San Diego: Academic Press; 1991. p. 303-15.

[29] Kyle UG, Genton L, Karsegard L, Slosman DO, Pichard D. Single prediction equation for bioelectrical impedance analysis in adults ages 20-94 y. Nutrition 2001;3:248-53.

[30] Schutz Y, Kyle UG, Pichard C. Fat-free mass index and fat mass index percentiles in Caucasians ages 18 to 98 y. Int J Obes Relat Metab Disord 2002;26:953-60.

[31] Piccoli A, Nigrelli S, Caberlotto A, Bottazzo S, Rossi B, Pillon L. Bivariate normal values of the bioelectrical impedance vector in adult and elderly populations. Am J Clin Nutr 1995;61:269-70.

[32] Hotelling $H$. The generalization of Student's ratio. Ann Math Statist $1931 ; 2: 360-78$.

[33] Cruz-Jentoft AJ, Baeyens JP, Bauer JM, Boirie Y, Cederholm T, Landi F, et al, European Working Group on Sarcopenia in Older People. Sarcopenia: European consensus on definition and diagnosis: report of the European Working Group on Sarcopenia in Older People. Age Ageing 2010;39:412-23.

[34] Ravaglia G, Forti P, Maioli F, Boschi F, Cicognani A, Gasbarrini G. Measurement of body fat in healthy elderly men: A comparison of methods. J Gerontol A Biol Sci Med Sci 1999;54:M70-6.

[35] Rolland Y, Lauwers-Cances V, Cournot M, Nourhashémi F, Reynish W, Rivière D. Sarcopenia, calf circumference, and physical function of elderly women: a cross-sectional study. J Am Geriatr Soc 2003;51:1120-4.

[36] Saragat B, Buffa R, Mereu E, Succa V, Cabras S, Mereu RM, et al. Nutritional and psycho-functional status in elderly patients with Alzheimer's disease. J Nutr Health Aging 2012;16:231-6.

[37] Buffa R, Mereu RM, Putzu PF, Floris G, Marini E. Bioelectrical impedance vector analysis detects low body cell mass and dehydration in patients with Alzheimer's disease. J Nutr Health Aging 2010;14:823-7.

[38] Shen W, St-Onge MP, Wang ZM, Heymsfield SB. Study of body composition: an overview. In: Heymsfield SB, Lohman TG, Wang Z, Going SB, editors. Human body composition, 2nd ed. Champaign, IL; Human Kinetics; 2005. p. 3-13.

[39] Kyle UG, Genton L, Hans D, Karsegard VL, Michel JP, Slosman DO, et al. Total body mass, fat mass, fat-free mass, and skeletal muscle in older people: cross-sectional differences in 60-year-old persons. J Am Geriatr Soc 2001;49:1633-40.

[40] Cohn SH, Vaswani AN, Yasumura S, Yuen K, Ellis KJ. Assessment of cellular mass and lean body mass by noninvasive nuclear techniques. J Lab Clin Med 1985;105:305-11.

[41] Dumler F. Hypoalbuminemia is a marker of overhydration in chronic maintenance patients on dialysis. ASAIO J 2003;49:282-6.

[42] Siervo M, Faber P, Gibney ER, Lobley GE, Elia M, Stubbs RJ, et al. Use of the cellular model of body composition to describe changes in body water compartments after total fasting, very low calorie diet and low calorie diet in obese men. Int J Obes (Lond) 2010;34:908-18.

[43] Jacobs LH, van de Kerkhof JJ, Mingels AM, Passos VL, Kleijnen VW, Mazairac AH, et al. Inflammation, overhydration and cardiac biomarkers in haemodialysis patients: a longitudinal study. Nephrol Dial Transplant 2010;25:243-8.

[44] Chumlea WC, Schubert CM, Sun SS, Demerath E, Towne B, Siervogel RM. A review of body water status and the effects of age and body fatness in children and adults. J Nutr Health Aging 2007;11:111-8.

[45] Mazariegos M, Kral JG, Wang J, Waki M, Heymsfield SB, Pierson RN, et al. Body composition and surgical treatment of obesity. Effects of weight loss on fluid distribution. Ann Surg 1992;216:69-73.

[46] Waki M, Kral JG, Mazariegos M, Wang J, Pierson RN Jr, Heymsfield SB. Relative expansion of extracellular fluid in obese versus non obese women. Am J Physiol 1991;261:E199-203.

[47] Baarends EM, Schols AM, van Marken Lichtenbelt WD, Wouters EF. Analysis of body water compartments in relation to tissue depletion in clinically stable patients with chronic obstructive pulmonary disease. Am J Clin Nutr 1997;65:88-94.

[48] Vilaça KH, Paula FJ, Ferriolli E, Lima NK, Marchini JS, Moriguti JC. Body composition assessment of undernourished older subjects by dual-energy $\mathrm{X}$-ray absorptiometry and bioelectric impedance analysis. J Nutr Health Aging 2011;15:439-43.

[49] Elmstahl A, Petersson M, Lilja B, Samuelsson SM, Rosen I, Bjuno L. Body composition in patients with Alzheimer's disease and healthy controls. J Clin Exp Gerontol 1992;14:17-31.

[50] Wirth R, Smoliner C, Sieber CC, Volkert D. Cognitive function is associated with body composition and nutritional risk of geriatric patients. J Nutr Health Aging 2011;15:706-10. 